\title{
LA ENSEÑANZA Y EL APRENDIZAJE DEL TIEMPO HISTÓRICO EN LA EDUCACIÓN PRIMARIA
}

\author{
Joan Pagès Blanch \\ Antoni Santisteban Fernández"
}

RESUMEN: El tiempo es un concepto muy complejo y sólo se entiende a partir de un análisis amplio y transdisciplinario. Cuando se enseña la historia a los niños se debe considerar esa complejidad remitiéndonos, por lo tanto, a nuevas representaciones del tiempo histórico. En este texto se destaca el papel de la didáctica de la historia para proponer un modelo conceptual de tiempo a través de la síntesis de diversas investigaciones sobre el tema. Por último se desea que la historia tenga significado para los niños como una herramienta para comprender mejor el presente de un pasado y aprender a intervenir en el futuro de un presente.

Palabras claves: Tiempo histórico. Enseñanza de la historia. Didáctica de la historia.

TEACHING AND LeARNING OF HISTORICAL TIME IN ELEMENTARY SCHOOLS

ABSTRACT: Time is a very complex concept that can only be understood from broad and transdisciplinary analyses. When teaching history to children such complexity should be considered, thus referring us to new representations of historical time. This text highlights the role of teaching history in the proposal of a conceptual model of time based on the synthesis of several investigations on

* Doctor en Ciencias de la Educación y profesor de la Universidad Autónoma de Barcelona. E-mail: joan.pages@uab.cat

** Doctor en Ciencias de la Educación y profesor de la Universidad Autónoma de Barcelona. E-mail: antoni.santisteban2@uab.cat

Cad. Cedes, Campinas, vol. 30, n. 82, p. 281-309, set.-dez. 2010

Disponível em <http://www.cedes.unicamp.br> 
that matter. Ultimately, it whishes that, for children, history had the meaning of a tool that helps them better understand the present of a past time and learn to intervene in the future time of a present.

Key words: Historical time. History teaching. History didactics.

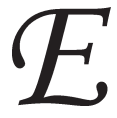

studiamos el tiempo para saber qué hora es, qué día es hoy, cuándo tenemos que celebrar los cumpleaños o para comprender por qué hay gente que no los quiere celebrar. Para poder decir qué pasaba en el mundo cuando yo nací, qué película hacían en los cines, qué canción se escuchaba, qué conflictos existían o quién mandaba, qué era noticia o cómo era mi ciudad. Para comprender los cambios y las continuidades en nuestro mundo, que es el mismo mundo de hace cien o mil años, pero muy diferente.

El tiempo es un concepto de gran complejidad y sólo lo podemos comprender desde una mirada amplia y transdisciplinar. El tiempo está presente en nuestra vida, una vida organizada alrededor del reloj, los horarios y el calendario. El tiempo está presente en nuestro lenguaje y nuestras actividades: esperamos, desesperamos, hacemos tiempo, perdemos, recortamos, alargamos el tiempo, damos o nos toman tiempo. El tiempo pasa rápido y lento, se acelera o, incluso, ¿se detiene? El tiempo es historia, la nuestra y la de todas las personas, es pasado colectivo, es interrelación de pasado, presente y futuro.

¿Cómo sabemos del tiempo? Sabemos que el tiempo pasa porque observamos los cambios en nuestro cuerpo o a nuestro alrededor. El tiempo es indisoluble con el espacio, tiempo y espacio no se pueden separar. Cada territorio, cada lugar acumula elementos que nos explican las transiciones y las rupturas, los conflictos de cada generación. La enseñanza del tiempo histórico debe hacerse teniendo en cuenta estas relaciones. Y lo mismo podemos decir de la enseñanza del espacio geográfico. El tiempo es muy importante para comprender la complejidad del territorio, para establecer las interrelaciones entre los diversos elementos de un paisaje (Pagès y Santisteban, 2009).

Cada época ha dado un significado diferente al tiempo, cada cultura vive la temporalidad desde la diversidad. No existe una única percepción del tiempo, sino una gran diversidad de experiencias y de representaciones. Una de las principales dificultades de adaptación de 
las personas a una nueva sociedad o a una nueva cultura es la manera como esta sociedad entiende el tiempo, es decir, su organización y su gestión, los protocolos de la espera, la secuencia de los hechos o de las acciones en la solución de los problemas. Ninguna otra cuestión ha fascinado tanto a la ciencia ficción como los viajes en el tiempo. La literatura y el cine se han planteado todo tipo de preguntas sobre este tema: ¿qué haríamos si pudiéramos viajar al pasado?, ¿podríamos cambiar la historia?

El tiempo y la historia

Quien pretende hacerse una idea corriente del tiempo histórico ha de prestar atención a las arrugas de un anciano o a las cicatrices en las que está presente un destino de la vida pasada. (Koselleck, 1993, p. 13)

La representación dominante aún del tiempo tiene sus orígenes a mediados del siglo XIX, derivada de la ciencia newtoniana. Su sistematización coincide con la creación de la historia como disciplina académica y su presencia en la enseñanza primaria. El tiempo histórico sirve para establecer los niveles de desarrollo y evolución de cada nación (Appleby, Hunt y Jacob, 1998) y, por extensión, del mundo occidental. El tiempo lineal, acumulativo, impuesto por Occidente para comprender su propia historia e impuesto, desde Occidente, al resto del mundo para comprender la de otras culturas y civilizaciones cada vez tiene más críticos.

Está emergiendo una nueva representación del tiempo histórico. La concepción newtoniana de un tiempo único deja paso a la multiplicidad de ritmos y de tiempos. Pero aún nuestra cultura está atrapada en una visión lineal del curso de la historia, que interpreta los cambios siempre como mejoras y como progreso olvidando que lo que para unos puede significar progreso, para otros puede representar decadencia. La historiografía más crítica reivindica una nueva concepción de la temporalidad para una nueva interpretación de la historia, que permita a la ciudadanía pensar futuros alternativos (Hobsbawm, 1998).

Este nuevo modelo de tiempo para la historia está siendo construido desde la multiplicidad y desde la interdisciplinariedad. No 
parece que el tiempo que estudia la filosofía, la psicología, la antropología o la física, por ejemplo, sea diferente, sino que existe un único concepto de tiempo observado desde diferentes perspectivas complementarias (Ramos, 1992). La historia es, en especial, una ciencia del tiempo y coincide con el resto de ciencias sociales en que el tiempo se explica como una estructura de conceptos: la memoria, las utopías, los cambios, la gestión del tiempo social, por ejemplo. Aunque el tiempo es lo que explica la existencia de la historia como pasado, la historia como ciencia que interpreta este pasado no ha aportado un modelo conceptual que nos permita elaborar un currículo para la enseñanza del tiempo histórico. El papel de la didáctica de la historia consiste en proponer un modelo conceptual sobre el tiempo, una síntesis de las diversas aportaciones para, en este caso, la enseñanza de la historia en la escuela primaria.

\section{La investigación y la enseñanza del tiempo histórico}

La primera gran obra sobre la percepción del tiempo y la construcción de las nociones temporales en la infancia es la Piaget (1978). Piaget organizó por primera vez una teoría global de desarrollo del concepto de tiempo en el aprendizaje humano, a partir de tres estadios, que corresponden al tiempo vivido, al tiempo percibido y al tiempo concebido, que también se han interpretado como tiempo personal, tiempo social y tiempo histórico. En la actualidad se ha recuperado su visión constructivista del aprendizaje, pero se ha criticado un cierto mecanicismo a la hora de plantear la adquisición de la temporalidad a una edad determinada.

Paul Fraisse (1967) continuó la línea de Piaget y realizó el trabajo más completo que existe sobre la construcción del concepto tiempo. Indagó en los factores que influyen en la percepción del tiempo. Por ejemplo, en el simple deseo de que el tiempo pase, en el aburrimiento, la espera o la prisa como factores decisivos en nuestra percepción del tiempo. A pesar de sus descubrimientos de esta nueva perspectiva de comprensión del tiempo, que Fraisse denominó "sensibilidad del tiempo", sus teorías no tuvieron el seguimiento que se podría esperar, al menos en las propuestas escolares para la enseñanza de la historia. 
En general no se ha hecho un buen uso de las teorías de Piaget, ya que se han aplicado de manera mecánica a la enseñanza de la historia (Calvani, 1988). Las críticas son diversas. En primer lugar, se considera que debe apreciarse más la importancia del lenguaje en la construcción de una narración temporal. Se ha demostrado, por ejemplo, que con materiales narrativos bien estructurados los niños y niñas reconocen mejor una estructura temporal lógica (Stein y Glenn, 1982). Algunas investigaciones demuestran que la velocidad no tiene un papel fundamental en la formación de la noción de tiempo (Montagero, 1984). La temporalidad se adquiere a partir de la comprensión progresiva de su estructura conceptual (Friedman, 1982). Pero la mayoría de investigaciones didácticas y psicológicas avanzan poco en este camino. Un gran número de trabajos se han destinado a establecer la edad de adquisición de la cronología, pero se sabe muy poco de las relaciones entre las vivencias sobre la temporalidad y el aprendizaje del tiempo histórico.

Algunos trabajos han demostrado que los niños y niñas de siete años ya dominan determinadas categorías temporales, como ordenar la secuencia de las edades de los miembros de su familia (Thornton y Vukelich, 1988). Otras investigaciones muestran la importancia que da el profesorado a la cronología, como un aspecto fundamental de la enseñanza de la historia, pero al final de la escolaridad obligatoria el alumnado no la domina (Pagès, 1999). El profesorado considera que el aprendizaje de la cronología es difícil, pero, en cambio, algunas investigaciones reconocen la capacidad del alumnado para identificar o explicar los cambios (Lautier, 1997).

Parece que al finalizar la escolaridad obligatoria los aprendizajes del alumnado sobre la historia están formados por una serie de elementos aislados, hechos, personajes y fechas, y algunos tópicos sobre conceptos como descubrimiento, revolución o progreso. Es como un cajón donde lo guardamos todo mezclado, donde tenemos una gran cantidad de objetos desorganizados, algunos de los cuales no sabemos ni tan sólo que los poseemos o no sabemos con qué relacionarlos. El aprendizaje del tiempo histórico puede ayudar a estructurar el conocimiento sobre la historia si se realiza teniendo en cuenta consideraciones como las siguientes:

a) La escuela debe superar la enseñanza de una historia de museo, que representa el tiempo histórico como una acumulación de datos y fechas. 
b) El aprendizaje del tiempo histórico debe basarse en las relaciones entre pasado, presente y futuro, a nivel personal y social.

c) La enseñanza de la historia ha de partir del tiempo presente y de los problemas del alumnado, para poder formar en valores democráticos (Evans, 1996; Audigier, 2003).

d) Se deben cuestionar las categorías temporales que se presentan como categorías naturales, cuando son construcciones sociales.

e) No sólo debemos enseñar una determinada periodización, sino que también debemos enseñar a periodizar (Ferro, 1991).

f) La cronología debe enseñarse relacionada con una serie de conceptos temporales básicos, como el cambio, la duración, la sucesión, los ritmos temporales o las cualidades del tiempo histórico (Stow y Haydn, 2000).

g) Los conceptos temporales actúan como organizadores cognitivos, tanto en los acontecimientos de la vida cotidiana como en el proceso de comprensión de la historia (Matozzi, 1988).

h) El pensamiento temporal está formado por una red de relaciones conceptuales, donde se sitúan los hechos personales o históricos de manera más o menos estructurada (Matozzi, 2002).

Actualmente existen diferentes propuestas que comienzan a caminar en esta línea, pero todavía dominan las enseñanzas basadas en una racionalidad positivista y en una concepción lineal del tiempo histórico. Una propuesta en la línea que planteamos la realizó Cooper (2002) para la educación infantil y primaria. Propone trabajar los siguientes aspectos del tiempo histórico: la medida del paso del tiempo; las secuencias cronológicas; la duración; las causas y las consecuencias de los cambios; las diferencias y las semejanzas entre el pasado y el presente; el lenguaje del tiempo; por último, el concepto de tiempo que los niños y niñas están construyendo.

\section{¿Qué debemos enseñar del tiempo histórico?}

La enseñanza de la historia en la escuela primaria ha de mostrar a los niños y niñas que el tiempo está presente en todas nuestras acciones 
o experiencias, en nuestro pensamiento, en nuestro lenguaje y en nuestras narraciones. La construcción de la temporalidad, sin embargo, se realiza durante toda la vida. La escuela puede ayudar a que los niños y niñas formen estructuras temporales cada vez más ricas y funcionales. En la educación primaria se establecen las bases del conocimiento histórico como conocimiento de la temporalidad, de la comprensión de los antecedentes, del pasado, que nos ayudan a comprender el presente y que, inevitablemente, nos ayudan a proyectar el futuro (Santisteban y Pagès, 2006).

Nuestro pensamiento necesita ordenar en el tiempo los hechos que tienen lugar a nuestro alrededor para poder comprender la realidad social. Nuestro lenguaje está plagado de términos, expresiones o conceptos temporales, que utilizamos para contestar a las preguntas ¿cuándo?, ¿en qué momento?, ¿en qué orden tuvieron lugar los acontecimientos? Los niños y niñas necesitan de un cierto lenguaje temporal para hablar o escribir de manera correcta, para explicar lo que han observado, lo que les ha sucedido en el pasado o para indicar sus deseos o sus necesidades de cara al futuro. Las primeras frases en la infancia están relacionadas con la comprensión de un cierto orden temporal en la narración oral.

En nuestras descripciones o en nuestras explicaciones aparecen verbos, adverbios, adjetivos, nombres, locuciones o frases hechas relacionadas con la temporalidad, que matizan en cada caso la idea de tiempo que queremos expresar o que ordenan los acontecimientos que estamos relatando. Este vocabulario es necesario para realizar narraciones coherentes y bien estructuradas, para ubicarnos en nuestra sociedad y poder comunicarnos con otras personas. La riqueza de estas narraciones aumentará cuando los niños y niñas adquieran un lenguaje más sofisticado, con más términos, con más elementos para la concreción de los hechos y con más posibilidades de combinación.

En el siguiente cuadro aparecen las diversas tipologías de términos relacionados con el lenguaje temporal. En cada caso se exponen algunos ejemplos, tal vez los más representativos de cada tipo de palabras, pero en ningún caso pretende ser una recopilación exhaustiva. Además, hay que tener en cuenta que pueden existir otro tipo de clasificaciones. Los términos de una misma tipología se dividen, según la dificultad que presentan para su aprendizaje, en dos columnas diferenciadas, una para los dos primeros cursos de educación primaria (6-8 
años) y los dos de la etapa intermedia (8-10 años) y otra que podría corresponder a los aprendizajes más adecuados para realizar a finales de la etapa intermedia (10 años) y en la etapa final (10-12 años). A mayor edad aumentan las capacidades para precisar más las medidas temporales o para concretar mejor la situación o la frecuencia temporal.

\section{Cuadro 1}

\section{TÉRMINOS RELACIONADOS CON LA TEMPORALIDAD}

\begin{tabular}{|l|l|l|}
\hline Tipo de palabras & $\begin{array}{l}\text { Vocabulario de términos } \\
\text { temporales: cursos iniciales } \\
(6 / 8) \text { e intermedios }(8 / 10)\end{array}$ & $\begin{array}{l}\text { Vocabulario de términos } \\
\text { temporales: cursos intermedios } \\
(8 / 10) \mathrm{y} \text { finales }(10 / 12)\end{array}$ \\
\hline
\end{tabular}

Formas básicas temporales en el uso del lenguaje

\begin{tabular}{|c|c|c|}
\hline Formas verbales & $\begin{array}{l}\text { Pasado (jugaba), presente (juego), } \\
\text { futuro (jugaré) }\end{array}$ & $\begin{array}{l}\text { Condicional (jugaria), } \\
\text { pretérito (jugara) }\end{array}$ \\
\hline $\begin{array}{l}\text { Verbos relacionados con la } \\
\text { duración }\end{array}$ & $\begin{array}{l}\text { Acontecer, comenzar, acabar, } \\
\text { durar }\end{array}$ & $\begin{array}{l}\text { Anticipar, acelerar, apresurarse, } \\
\text { ralentizar }\end{array}$ \\
\hline $\begin{array}{l}\text { Verbos relacionados con el } \\
\text { cambio }\end{array}$ & $\begin{array}{l}\text { Cambiar, crecer, madurar, } \\
\text { envejecer }\end{array}$ & $\begin{array}{l}\text { Evolucionar, renovar, } \\
\text { transformar, progresar }\end{array}$ \\
\hline $\begin{array}{l}\text { Verbos relacionados con la } \\
\text { espera }\end{array}$ & $\begin{array}{l}\text { Quedar (a una hora), esperar, } \\
\text { tardar }\end{array}$ & $\begin{array}{l}\text { Desesperar, esperanzar, anhelar, } \\
\text { añorar }\end{array}$ \\
\hline $\begin{array}{l}\text { Adverbios de localización } \\
\text { temporal }\end{array}$ & $\begin{array}{l}\text { Cuando. } \\
\text { Antes, ahora, después. } \\
\text { Ayer, hoy, mañana }\end{array}$ & $\begin{array}{l}\text { Anteriormente, posteriormente, } \\
\text { Simultáneamente }\end{array}$ \\
\hline $\begin{array}{l}\text { Adverbios que indican la } \\
\text { frecuencia temporal }\end{array}$ & $\begin{array}{l}\text { Pronto, seguidamente, despacio, } \\
\text { todavía, aún, mientras, entonces }\end{array}$ & $\begin{array}{l}\text { Siempre, nunca, jamás, } \\
\text { sucesivamente }\end{array}$ \\
\hline Adjetivos ordinales & Primero, segundo, último & Inicial, final \\
\hline $\begin{array}{l}\text { Adjetivos relacionados con } \\
\text { la velocidad (tiempo) }\end{array}$ & Rápido, lento, urgente & Pausado, acelerado, veloz \\
\hline $\begin{array}{l}\text { Adjetivos que indican } \\
\text { diferenciación temporal }\end{array}$ & $\begin{array}{l}\text { Nuevo, joven, viejo } \\
\text { Antiguo, moderno, actual }\end{array}$ & $\begin{array}{l}\text { Perenne, caduco } \\
\text { Nómada, sedentário }\end{array}$ \\
\hline \multicolumn{3}{|c|}{ Términos temporales concretos de uso cotidiano } \\
\hline El día y la partes del día & $\begin{array}{l}\text { Jornada, mañana, mediodia, } \\
\text { tarde, noche }\end{array}$ & $\begin{array}{l}\text { Madrugada, alba, atardecer, } \\
\text { crepúsculo, vigilia, velada }\end{array}$ \\
\hline $\begin{array}{l}\text { Estaciones/actividades } \\
\text { estacionarias }\end{array}$ & $\begin{array}{l}\text { Primavera, verano, otoño, } \\
\text { invierno }\end{array}$ & Hibernación, letargo, estiaje \\
\hline
\end{tabular}




\begin{tabular}{|c|c|c|}
\hline Medidas temporales & $\begin{array}{l}\text { Segundo, minuto, hora, semana, } \\
\text { mes, año }\end{array}$ & Siglo, milênio \\
\hline $\begin{array}{l}\text { Nombres para la } \\
\text { localización temporal }\end{array}$ & $\begin{array}{l}\text { Lunes, martes, miércoles,... } \\
\text { Enero, febrero, marzo,... }\end{array}$ & $\begin{array}{l}\text { Día de la Constitución, } \\
\text { aniversario, fin de semana, } \\
\text { Semana Santa, Fin de Año, Año } \\
\text { Nuevo, año bisiesto }\end{array}$ \\
\hline $\begin{array}{l}\text { Fracciones o conjuntos } \\
\text { temporales }\end{array}$ & Cuarto (hora), quincena, trimestre & $\begin{array}{l}\text { Cuarentena, trienio, década, } \\
\text { lustro }\end{array}$ \\
\hline Tiempos no definidos & Instante, momento, rato & $\begin{array}{l}\text { Contratiempo, intervalo, } \\
\text { temporada, periodo }\end{array}$ \\
\hline $\begin{array}{l}\text { Términos relacionados con } \\
\text { las edades }\end{array}$ & Cumpleaños, infancia, juventud & Adolescencia, ancianidad \\
\hline $\begin{array}{l}\text { Términos relacionados con } \\
\text { el ciclo de la vida }\end{array}$ & Nacimiento, muerte, crecimiento, & $\begin{array}{l}\text { Genealogia, linaje, ascendencia, } \\
\text { descendência }\end{array}$ \\
\hline Instrumentos temporales & Reloj, Calendario & Cronómetro \\
\hline \multicolumn{3}{|c|}{ Expresiones de carácter temporal } \\
\hline Locuciones adverbiales & $\begin{array}{l}\text { Ahora mismo, en punto, de } \\
\text { seguida, lo más pronto posible, } \\
\text { poco a poco, a menudo, a veces, de } \\
\text { vez en cuando, a todas horas, hasta } \\
\text { ahora, de ahora en adelante, a } \\
\text { continuación, esta mañana, toda } \\
\text { la tarde, a última hora, en una } \\
\text { ocasión, a partir de..., a mediados } \\
\text { de..., al cabo del tiempo }\end{array}$ & $\begin{array}{l}\text { Al instante, de repente, cuanto } \\
\text { antes mejor, a ratos, de tanto en } \\
\text { tanto, mientras tanto, al mismo } \\
\text { tiempo, a destiempo, antes de } \\
\text { hora, en mala hora, a buena } \\
\text { hora, a media tarde, entrada la } \\
\text { noche, a las tantas, de sol a sol, } \\
\text { entre semana, tarde o temprano, } \\
\text { a la hora de la verdad, hoy en } \\
\text { día, hoy por hoy, tal día como } \\
\text { hoy, en la vida, nunca más, por } \\
\text { siempre más }\end{array}$ \\
\hline $\begin{array}{l}\text { Frases hechas sobre la } \\
\text { temporalidad }\end{array}$ & $\begin{array}{l}\text { La semana que viene, el año } \\
\text { pasado, había una vez, cuando el } \\
\text { Sol sale, acabado de hacer, ir a la } \\
\text { hora, ya era hora, ser más largo } \\
\text { que un día sin pan }\end{array}$ & $\begin{array}{l}\text { Cuando el gallo canta, romper el } \\
\text { día, ir a toda vela, robar horas al } \\
\text { sueño, entrar en años, quitarse } \\
\text { años, hacerse eterno, ir al otro } \\
\text { barrio, volver a nacer }\end{array}$ \\
\hline $\begin{array}{l}\text { Frases hechas con el } \\
\text { término tiempo }\end{array}$ & $\begin{array}{l}\text { Perder el tiempo, ganar tiempo, no } \\
\text { tener tiempo, dar tiempo, pasar el } \\
\text { tiempo, controlar el tiempo, estar a } \\
\text { tiempo }\end{array}$ & $\begin{array}{l}\text { El tiempo es oro, estar fuera de } \\
\text { tiempo, vivir en tiempos } \\
\text { diferentes, coincidir en el tiempo, } \\
\text { robar el tiempo, tener tiempo que } \\
\text { perder, matar el tiempo, pedir } \\
\text { tiempo }\end{array}$ \\
\hline Refranes & $\begin{array}{l}\text { A quien madruga Dios le ayuda. } \\
\text { No por mucho madrugar amanece } \\
\text { más temprano. } \\
\text { En abril aguas mil }\end{array}$ & $\begin{array}{l}\text { Hasta el cuarenta de mayo no te } \\
\text { quites el sayo } \\
\text { El tiempo lo cura todo } \\
\text { El tiempo nos hace a todos iguales }\end{array}$ \\
\hline
\end{tabular}


Los cuentos que explicamos en la escuela o las mismas narraciones que construye el alumnado pueden ser recursos importantes para el aprendizaje de conceptos temporales. A la vez, el uso de la narración se convierte en un instrumento importante en la construcción de la temporalidad en los niños y niñas. Las actividades relacionadas con el tiempo de nuestra vida cotidiana, con la organización del horario y de las actividades diarias, ayudarán también al alumnado a comprender la importancia de la gestión del tiempo en su experiencia social.

El lenguaje temporal es fundamental en la narración histórica. Para la construcción de la historia necesitamos ordenar y clasificar temporalmente los acontecimientos del pasado. Además de un determinado lenguaje narrativo en relación con el tiempo, necesitamos que el conocimiento conceptual del tiempo histórico se convierta en uno de los aspectos más importantes del aprendizaje de la historia en la escuela primaria (Santisteban, 2009).

En demasiadas ocasiones el aprendizaje del tiempo y del tiempo histórico se relaciona únicamente con el conocimiento de las medidas temporales, es decir, con el estudio del reloj, del calendario o de la cronología histórica. Pero el tiempo histórico necesita de la comprensión de los diversos conceptos que forman nuestra temporalidad, por ejemplo las relaciones entre el pasado, el presente y el futuro, la comprensión del cambio y el significado del progreso (Pagès y Santisteban, 1999; Santisteban, 1999; Pagès, 2004). Estos conceptos son de una gran amplitud y se construyen desde su aplicación a realidades diversas, como la vida cotidiana, la historia familiar o la historia de una nación.

Además del lenguaje temporal, las personas necesitamos comprender una serie de conceptos que dan significado a la idea de tiempo histórico, ya que en realidad el tiempo es un concepto de conceptos. Para poder saber cuáles son las estructuras conceptuales que explican o que nos ayudan a explicar el tiempo histórico, nos hacemos cuatro preguntas fundamentales:
a) ¿Qué es el tiempo y el tiempo histórico?
b) ¿Qué es la temporalidad humana?
c) ¿Cómo sabemos que ha pasado el tiempo?
d) ¿Quién tiene el poder sobre el tiempo? 
Joan Pagès Blanch \& Antoni Santisteban Fernández




¿Qué es el tiempo y el tiempo histórico?

En primer lugar, necesitamos saber que el tiempo es irreversible, que no lo podemos recorrer hacia atrás. Por otro lado, el tiempo no se puede separar del espacio, porque es en el terreno de lo físico que observamos los cambios, ya sea en un paisaje, en la cara de un anciano o las herramientas y utensilios que usamos en nuestra vida diaria. El tiempo es relativo ya que es percibido de manera diferente por cada persona y cada cultura representa el tiempo de una manera distinta.

La dificultad de la comprensión del tiempo está relacionada con la gran cantidad de significados que tiene. Su significado es distinto si, por ejemplo, lo aplicamos a la ciencia - se habla de tiempo físico o biológico -, a las creencias religiosas - la inmortalidad o la eternidad del tiempo -, o en el campo de la experiencia de tiempo personal o social (nunca tenemos tiempo para realizar todo aquello que queremos realizar). En nuestro pensamiento diferenciamos también un tiempo finito o infinito, cíclico o lineal, objetivo o subjetivo.

\section{¿Qué es la temporalidad humana?}

La temporalidad humana incluye tres conceptos de amplio significado: pasado, presente y futuro. Conocemos el pasado a partir de las fuentes, los documentos o el patrimonio histórico. El estudio del pasado incluye elementos de nuestra memoria individual, de nuestros recuerdos, así como de la memoria colectiva o de la memoria histórica. En el siguiente cuadro aparecen las reflexiones de un niño sobre el concepto de la memoria aplicada al ámbito familiar.

El presente es un fragmento temporal, un nexo de unión, entre lo que ya ha sido - el pasado - y lo que será, lo que está por llegar - el futuro. La historia personal o familiar de nuestro alumnado es de alguna manera historia del presente, la historia próxima en el tiempo. La historia que más cerca está del futuro.

El futuro tiene diferentes formas de concretarse. Las religiones nos muestran futuros diferentes que van más allá de nuestras vidas. Las ideologías nos presentan utopías políticas o sociales, con expectativas más o menos realistas. La ciencia utiliza el concepto de prospectiva, 
como una forma de entender nuestra capacidad intelectual de prever lo que puede pasar, así como el camino que se debería seguir en el futuro teniendo en cuenta el pasado.

\section{Figura 2}

Reflexiones de un niño sobre el concepto de la memoria aplicada al ámbito familiar

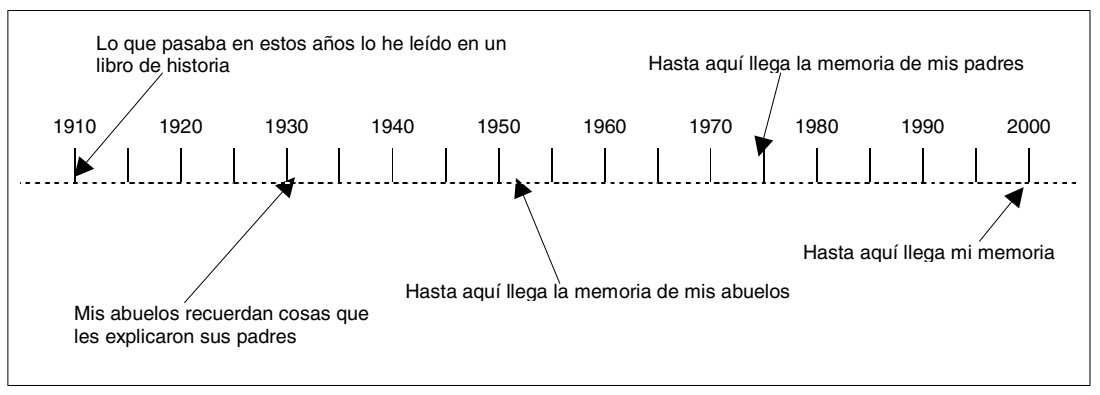

¿Cómo sabemos que ha pasado el tiempo?

El tiempo pasa porque las cosas cambian. El concepto de cambio va unido al de continuidad. En cualquier realidad existen cambios y continuidades. También en las personas se producen cambios, ya que cambiamos a cada segundo desde un punto de vista biológico, pero siempre somos la misma persona. Cuando estudiamos la historia de nuestra localidad señalaremos los aspectos de cambio, de crecimiento urbano o de transformación del paisaje, pero también hemos de indicar los elementos que permanecen sea en la estructura urbana, en los campos y en las calles o en las evidencias en forma de monumentos, de tradiciones, de recuerdos o de otros elementos que configuran el patrimonio cultural e histórico.

Los cambios tienen un ritmo y una intensidad, se aceleran o se hacen más lentos. Para significar el ritmo y la intensidad del cambio se habla de evolución o de revolución. Si el cambio se analiza a partir de criterios cuantitativos aparecen conceptos como los de crecimiento o desarrollo. O se habla de transición o de transformación según la madurez del proceso de cambio. La visión positiva o negativa 
La enseñanza y el aprendizaje del tiempo histórico en la educación primaria

de los cambios históricos se relaciona con el progreso o la decadencia. Todos estos conceptos relacionados con el cambio son utilizados por la historia para la interpretación de la sociedad de cada época.

\section{Figura 3}

El cambio y la continuidad

\begin{tabular}{|l|c|c}
\hline \multicolumn{3}{|c}{ El vestido } \\
\hline El pasado & El presente & El futuro \\
\hline & & \\
\hline
\end{tabular}

En la educación primaria los temas que se trabajan desde una perspectiva diacrónica ayudan al alumnado a comprender mejor los cambios. Temas como los propuestos por Cousinet - la historia del vestido, 
la evolución de la vivienda o de la escritura - facilitan la comparación de una misma situación en distintas épocas históricas, así como las diferencias entre el pasado y el presente. Los alumnos de primaria han de plantearse cómo son y cómo eran y cómo se imaginan que serán en el futuro, los vestidos, las casas o cómo se comunicarán las personas y por qué hay cambios y continuidades. Veamos de una manera gráfica cómo se pueden trabajar los cambios en los primeros cursos de primaria.

\section{¿Quién tiene el poder sobre el tiempo histórico?}

\section{El poder sobre el tiempo lo tiene quien lo sabe organizar}

Una de las formas de poder sobre el tiempo tiene relación con nuestra capacidad para dominar nuestro propio tiempo, el de nuestra vida diaria, el tiempo de trabajo y el tiempo de ocio, la organización equilibrada del tiempo disponible. Nuestra capacidad organizativa puede favorecer nuestra autonomía. Un ejercicio útil con los niños y niñas de 8 a 10 años es que realicen de una manera gráfica su horario personal y que, después, hagan una propuesta de mejora de su organización temporal. El proceso puede comenzar con una actividad de ordenación temporal de las actividades que un niño o una niña realiza a lo largo del día.

\section{El poder sobre el tiempo lo tiene quien sabe medir el tiempo}

Dominar la cronología o los instrumentos de medición del tiempo ha sido siempre una forma de dominio social. Los calendarios o los relojes han sido formas de controlar los ritmos de la vida de las personas, unos en las sociedades agrícolas y otros en las industriales. La cronología corresponde a la representación de un tiempo objetivo, que necesitamos para situar los acontecimientos históricos, así como para ordenarlos en una sucesión o, en algunos casos, para decidir la simultaneidad de los hechos. Sin embargo, la cronología no nos dice nada sobre la calidad o el valor de lo que se mide. La cronología no es el tiempo histórico. Es un requisito para aprenderlo pues sitúa los cambios y las continuidades pero no los explica. 
El poder sobre el tiempo lo tiene quien sabe periodizar y narrar la historia

A diferencia de la cronología, la periodización histórica corresponde a una representación cualitativa del tiempo, ya que los períodos históricos no son regulares, es decir, no tienen una duración equivalente. Por ejemplo, el Paleolítico tiene una duración mucho mayor que el Neolítico, y la Edad Media varios siglos más que la Edad Moderna. Lo que marca el paso de un período histórico a otro son cambios que afectan las estructuras sociales existentes, la organización política, la economía, la cultura y la vida de las personas en general. La periodización es una parte de la construcción de la historia que ayuda a estructurar también la narración histórica. Comprender la periodización también es una forma de dominio o de control sobre el tiempo histórico.

En los primeros cursos de la educación primaria la periodización se puede relacionar, en primer lugar, con las diferencias que establecemos en el lenguaje, para distinguir lo que es antiguo de lo que es moderno, como una primera aproximación a la clasificación y la ordenación de los acontecimientos. Posteriormente, otro tipo de periodización se puede relacionar con las distintas generaciones que conviven en una familia, la que pertenece al tiempo de los abuelos, de los padres etc.

\section{El poder sobre el tiempo lo tiene quien ayuda a construir el futuro}

La construcción voluntaria del futuro, la intervención social para mejorarlo, es otra forma de poder sobre el tiempo. Es evidente que el futuro debe abordarse desde la prospectiva científica de la historia, a partir del conocimiento del pasado. El futuro debe ser objeto de enseñanza como un aspecto importante de la formación democrática de la ciudadanía. Construir el futuro desde la intervención social requiere, en primer término, la reflexión sobre los diversos futuros: posibles, probables y deseables (Whitaker, 1997; Hicks, 2006). Veamos el dibujo de un niño de 11 años donde se imagina cómo será dentro de 50 años el riachuelo - totalmente seco la mayor parte del tiempo - que cruza su barrio y que está sin urbanizar y sin ningún uso ciudadano (ciudad de la provincia de Barcelona). 


\section{Figura 4}

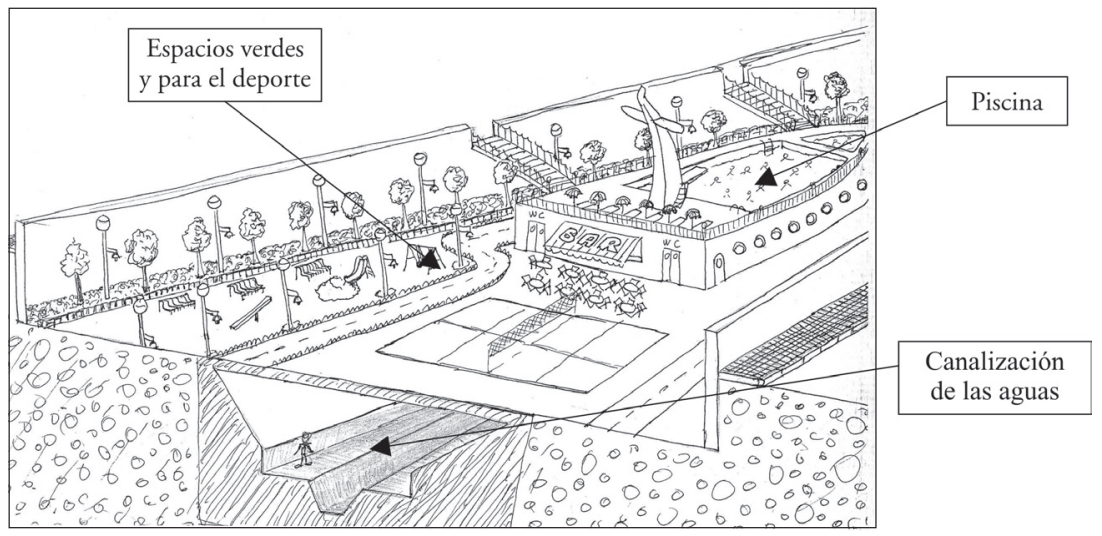

¿Cómo debemos enseñar el tiempo histórico?

Cuando se pretende que el alumnado desarrolle su pensamiento sobre el tiempo, las fuentes históricas se convierten en elementos centrales del proceso de enseñanza y aprendizaje. Algunas de las razones que permiten comprender el valor educativo de las fuentes históricas, en relación con la construcción de la conciencia temporal, son (Santisteban y Pagès, 2006):

a) ayudan a superar la estructura organizativa de los libros de texto a partir de actividades sobre la historia familiar y local y de procedimientos para relacionar pasado y presente;

b) permiten conocer la historia más próxima y establecer generalizaciones y relaciones con otras realidades y con otras temporalidades;

c) generan un conocimiento histórico concebido como un conocimiento discutible, producido en el tiempo;

d) presentan aspectos de la vida de las personas más allá de los acontecimientos bélicos o políticos, y favorecen la comprensión de los cambios en la vida; 
e) facilitan que el alumnado entre con mayor rapidez dentro del contenido problemático de la disciplina;

f) ponen en juego el concepto de objetividad frente al manual o al texto historiográfico, y ayudan a comprender como se construye la historia y el tiempo histórico;

g) permiten contemplar aquello que pasó en una especie de "estado natural", al margen de manipulaciones y con la posibilidad de planificar una utilización didáctica articulada, que ponga en contacto directo al alumnado con el pasado;

h) facilitan el protagonismo del estudiante en su propia reconstrucción de la historia.

La información que nos aportan las fuentes primarias presenta problemas en función de su intencionalidad, parcialidad, diversidad, multiplicidad de temas, de formas y de orígenes. Hace que tengamos que seleccionar cuidadosamente y presentar una gama de ejemplos suficientes, que permitan una interpretación coherente de los aspectos que pretendemos conocer. A pesar de todo, debemos tener en cuenta que su diversidad representa una gran riqueza para el aprendizaje, para los procesos de formación del pensamiento histórico.

Las fuentes nos permiten comprender los cambios, así las fuentes estadísticas nos ofrecen datos objetivos para comprender una realidad anterior. Un ejemplo es la relación de precios de principios del siglo Xx (1900) en diferentes ciudades españolas. El cálculo del coste de la alimentación de una familia de cuatro o cinco miembros sirve para descubrir las dificultades de subsistencia en esta época. Y explica, en parte, el trabajo infantil o la explotación a la que estaban sometidas las familias obreras.

Una información como la de este ejemplo permite, además, plantear la desigualdad de los salarios de los hombres y las mujeres. También se pueden comparar estos precios y los salarios con los actuales, así como comparar el presupuesto familiar, el tipo de gastos etc. Los oficios que aparecen en la lista nos dan la oportunidad de observar los cambios que se han producido en el trabajo. Algunos oficios han desaparecido y otros se han transformado debido a la mecanización, a la informática o a la robótica. Otros oficios se mantienen y lo que ha cambiado es la forma de practicarlos. 


\section{Cuadro 2}

\begin{tabular}{|l|l|l|l|}
\hline Precios & Pesetas & Salarios por día & Pesetas \\
\hline Pan & 0.35 & Oficial carpintero & 4.00 \\
\hline Carne & 1.80 & Cantero & 4.00 \\
\hline Tocino & 1.75 & Albañil & 4.00 \\
\hline Alubias & 1.25 & Peón albañil & 2.50 \\
\hline Garbanzos & 2.15 & Oficial cerrajero & 4.00 \\
\hline Patatas & 0.15 & Oficial aserrador & 4.16 \\
\hline Bacalao & 1.30 & Oficial calderero & 4.00 \\
\hline Arroz & 0.55 & Oficial fundidor & 4.00 \\
\hline Azúcar & 0.95 & Oficial panadero & 4.00 \\
\hline Aceite (litro) & 1.30 & Oficial sombrerero & 4.00 \\
\hline Vino (litro) & 0.55 & Oficiala sombrerera & 2.00 \\
\hline Botas & 11.00 & Costurera & 2.50 \\
\hline Tela Mahón (vara) & 1.00 & Estampadores & 4.00 \\
\hline Jabón (kilo) & 0.60 & Tejedores mecánicos & 3.16 \\
\hline
\end{tabular}

Fuente: Elaborado a partir de Tuñón de Lara (1985): El movimiento obrero en la historia de España. Barcelona: Laia, 1985.

En el aprendizaje de la temporalidad, las fuentes audiovisuales contemporáneas, especialmente las imágenes fotográficas, son de fácil reproducción y manipulación, aunque las imágenes cinematográficas o los documentos sonoros, por ejemplo de la radio, pueden ser fuentes históricas complementarias. Las fotografías tienen un gran potencial educativo que está unido a sus propias características:

a) La fotografía no es un vestigio involuntario como una herramienta agrícola desgastada o vieja que se abandona, sino voluntario, realizado expresamente para dejar constancia de algo. 
b) No es un indicio, sino una señal creada para conservarse como vestigio, para conservar y transmitir un mensaje, para ser memoria (Sega, 1986).

c) La fotografía representa la popularización del retrato y del sentimiento para conservar la identidad.

d) En las clases populares, la fotografía substituyó a la memoria oral.

e) La fotografía no posee un orden racional (lógico-narrativo) ni puede ser totalmente decodificada: deja un espacio importante a las interpretaciones subjetivas y emotivas.

f) La imagen no requiere una decodificación digital como el lenguaje verbal, sino analógica, necesita una visión global y una evaluación de lo esencial y de lo accesorio.

\section{Figuras 5 e 6}


Todas las familias tienen fotografías antiguas que pueden servir como ejemplos para iniciar a los niños y niñas en la interpretación histórica. Estas imágenes, que el alumnado puede aportar a la clase de historia, abarcan una gran diversidad de aspectos de la vida pasada de las personas: trabajo, fiesta, transportes, costumbres, guerra, estudios, vestidos, paisaje... La escuela puede convertirse en un museo o en una 
exposición permanente de la historia familiar del alumnado. A través de su historia familiar se pueden introducir temáticas del pasado de la localidad o del país. Con las diferentes fotografías podemos descubrir los cambios y las continuidades en aspectos concretos de la evolución humana e iniciar al alumnado en la causalidad histórica (¿por qué han cambiado los transportes terrestres?, ¿por qué perduran determinados edificios como las iglesias? etc.).

Las fotografías no sólo ayudan a la comprensión del cambio y la continuidad sino que permiten la comparación en el tiempo - con otros períodos, con el presente - y en el espacio - con otros países, con otras culturas. Una posibilidad son los cambios que se han dado en el espacio urbano en los últimos cien años. Veamos el ejemplo de una ciudad de la provincia de Barcelona, donde podemos observar cómo ha cambiado su actual calle principal con respecto a 1904 .

\section{Figuras 7 e 8}
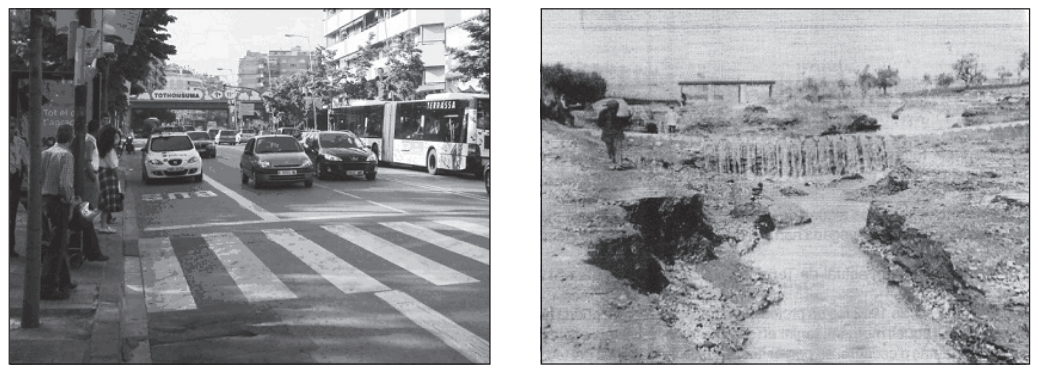

Otro tipo de fuentes son las fuentes orales, que ponen al alumnado en contacto directo con los testimonios y facilitan la comprensión del tiempo histórico. Las fuentes orales son fundamentales para un estudio vivo de la historia que ayude en la construcción de la conciencia histórica. Ayudan también en el desarrollo de habilidades para la búsqueda y el tratamiento de información, en el desarrollo de cuestionarios para las entrevistas, las grabaciones, la interpretación de los resultados en el aula y la interpretación. Las fuentes orales favorecen el paso de la historia personal o familiar a la historia colectiva, y sus diversos tiempos históricos. 
¿Cómo se construye el tiempo histórico en la educación primaria?

La historia personal es un recurso importante en la construcción del pensamiento y del tiempo histórico del alumnado de educación primaria. Es evidente que la historia presenta una complejidad conceptual y procedimental que debe afrontarse a partir de realidades asequibles a los niños y niñas. La utilización de la historia personal como objeto de estudio nos permite disponer de un campo de aplicación para los diferentes conceptos relativos del tiempo histórico, así como otros conocimientos de la historia más factual. La historia personal es un campo de entrenamiento para plantear cuestiones relativas al conocimiento de su tiempo, a la cronología, a los períodos de su vida, a los acontecimientos destacables, a los cambios más importantes, a los documentos oficiales o privados que conserva su familia etc.

La historia personal no es tan sólo un aprendizaje de la temporalidad, ayuda en el desarrollo fundamental de las capacidades narrativas (Bruner, 1990), en el análisis de las fuentes, de las capacidades metacognitivas (Girardet, 1996 y 2001) y, también, en la comparación cronológica y en la relación con acontecimientos históricos simultáneos o paralelos. Según Girardet (1996, p. 146-147):

(...) la elevada "competencia narrativa" de la que estos niños dan muestras - y que la escuela parece ignorar ya sea porque efectivamente no la conoce, ya sea porque no organiza tiempos y espacios para hacerlo aflorar - constituye un potencial de gran importancia sobre el que articular la adquisición de nuevos conocimientos disciplinares, en particular los de tipo narrativo, como son los conocimientos sociales e históricos (...). Queda claro que contar la propia historia constituye una experiencia muy enriquecedora para los niños, que es muy distinta de la de "relatar" conocimientos históricos referidos a situaciones no experimentadas y lejanas, tanto en el tiempo como por el tipo de fenómenos tratados.

Proponemos a continuación un proceso de construcción de la historia personal. El proceso puede seguir los pasos siguientes:

1) Recoger información de la propia historia con los aspectos esenciales que caracterizan su tiempo histórico: pasado (fuentes), presente y futuro, cambio y continuidad. 
2) Periodizar la historia personal a partir de la información recogida anteriormente, por ejemplo periodizar a partir de los ciclos educativos.

3) Buscar los elementos de simultaneidad que pudieran existir entre la historia personal y los hechos históricos a nivel local o nacional. Se puede comenzar por indagar lo que pasaba en su entorno en el año de su nacimiento.

4) Clasificar y ordenar la información para proceder a la narración de la historia personal, comenzando por aquello que pasaba antes de nacer, en el año que nacieron y continuando por cada período histórico, para acabar con sus expectativas de futuro.

\section{Cuadro 3}

\begin{tabular}{|c|c|c|c|c|c|c|}
\hline & Paisaje & Vivienda & Alimentación & $\begin{array}{l}\text { Tecnología/ } \\
\text { Transportes }\end{array}$ & $\begin{array}{l}\text { Creencias/ } \\
\text { Arte }\end{array}$ & $\begin{array}{c}\text { Organización/ } \\
\text { Poder }\end{array}$ \\
\hline Paleolítico & & & & & & \\
\hline Neolítico & & & & & & \\
\hline Iberos & & & & & & \\
\hline Romanos & & & & & & \\
\hline Edad Media & & & & & & \\
\hline Edad Moderna & & & & & & \\
\hline $\begin{array}{l}\text { Edad } \\
\text { Contemporánea } \\
\text { Siglo XIX }\end{array}$ & & & & & & \\
\hline $\begin{array}{l}\text { Edad } \\
\text { Contemporánea } \\
\text { Siglo XX }\end{array}$ & & & & & & \\
\hline Futuro & & & & & & \\
\hline
\end{tabular}

Otra forma de trabajar el tiempo histórico en los últimos cursos de la educación primaria (10-11 años) es representando la periodización histórica en un mural. En éste aparecerán los períodos históricos, 
relacionados con diferentes aspectos de la vida de las personas, de la organización social y de la cultura. El mural puede ocupar una de las paredes de la clase y cada apartado debe recoger un dibujo del alumnado y una frase explicativa (cuadros tamaño A-4).

El proceso de trabajo implica la búsqueda de información, la representación esquemática y la síntesis de ideas, la exposición en grupo y la reconstrucción de los conocimientos adquiridos, a partir de la lectura de la imagen y de la comprensión de las aportaciones del resto del alumnado. El trabajo autónomo del alumnado permite al profesorado trabajar con los grupos o con los niños y niñas que considere más oportuno, lo que facilita el diálogo interpersonal y el aprendizaje individualizado. Veamos un ejemplo de un dibujo de una niña de 12 años sobre el paisaje del Neolítico.

\section{Figuras 9}

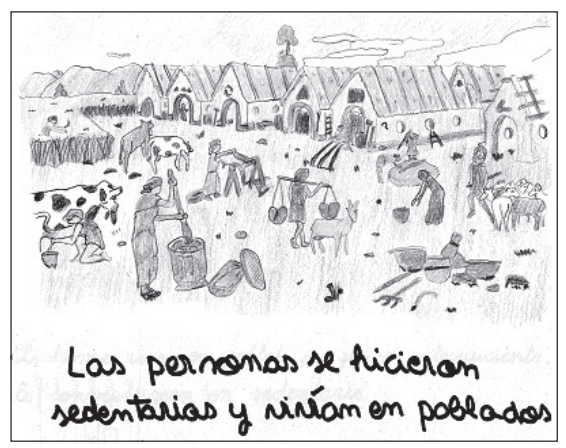

El proceso de trabajo puede ser el siguiente: a) por grupos se reparten los diferentes cuadros del mural, de tal manera que cada grupo se encarga de una época histórica; b) cada grupo trabaja con los libros de la biblioteca de la clase y busca la información pertinente con la ayuda del maestro o maestra; c) se dibuja cada cuadro y se debate en el grupo qué frase es la más indicada para expresar ese aspecto en esa época histórica; d) cada vez que un grupo acaba uno de los cuadros se coloca en el mural; e) cuando el mural está acabado, cada grupo explica las características esenciales de la época histórica que les ha tocado; 
f) cuando todos los grupos han expuesto sus trabajos, cada alumno o alumna realiza un informe a partir de la lectura horizontal de cada época histórica, así como de la lectura vertical de cada aspecto tratado en su evolución a lo largo del tiempo.

El mural es algo parecido a un mosaico de la historia, pero, en realidad, para el alumnado es una especie de mapa temporal donde situar los acontecimientos de la historia, así como también una forma de visualizar el cambio y la continuidad. Es un instrumento para que sitúen los acontecimientos y cambios en el tiempo, para que ellos mismos se sitúen en el tiempo histórico.

Una de las dificultades con la que se puede encontrar el alumnado de la enseñanza primaria tiene relación con la duración y su representación cronológica. Existen algunos recursos al respecto relacionados con la construcción de las líneas del tiempo. Uno de ellos es la traducción de la evolución histórica, desde los orígenes a la actualidad, a partir de la historia de un día (la duración de las sociedades recolectoras y cazadoras se inicia a las cero horas de un día y va hasta las seis de la tarde del mismo día, momento en el que empiezan las sociedades agrícolas y ganaderas. El último minuto del día corresponde al período que va desde la finalización de la II Guerra Mundial hasta la actualidad).

Una actividad parecida a la anterior puede realizarse proyectando el devenir histórico en un período de cinco minutos. Se buscan unas imágenes de cada uno de los períodos en los que dividamos el pasado humano y se proyectan durante un tiempo equivalente a su duración real (por ejemplo: sociedades cazadoras y recolectoras desde hace un millón de años hasta el 3000 aC: 4 minutos; sociedades agrícolas y ganaderas y primeras civilizaciones - del $3000 \mathrm{aC}$ al 500 d.C: 30 segundos; sociedades feudales europeas - del 500 al 1200: 15 segundos; sociedades urbanas europeas - 1200 al 1750-: 8 segundos; sociedades industriales - 1750 a 1945: 6 segundos; actualidad: 1 segundo) (Pagès, 1989). Estas actividades facilitan al alumnado la comprensión de unas duraciones tan extensas, y tan abstractas para sus cortas vidas, que si no las visualiza o las concreta se le escapa su significado real, aún en términos matemáticos (años transcurridos desde el inicio o final de cada período en relación con el presente). 
Quisiéramos conseguir, con estas actividades, que la historia fuera para el alumnado algo más que un conjunto de elementos aislados, de nombres, fechas e ideas sin ningún orden ni concierto, como aquel cajón donde guardamos un montón de cosas desordenadas, sin ninguna relación y, por tanto, sin ninguna utilidad. Quisiéramos que la historia tuviera significado para los niños y niñas, como un instrumento para comprender mejor el presente desde el pasado y para aprender a intervenir en el futuro desde el presente.

Recebido em junho de 2009 e aprovado em novembro de 2009.

\section{Referencias}

APPLEBY, J.; HUNT, L.; JACOB, M. La verdad sobre la historia. Barcelona: Andres Bello, 1998.

AUDIGIER, F. Histoire scolaire, formation citoyenne et recherches didactiques. In: Baques, M.C.; Bruter, A.; Tutiaux-Guillon, N. (Org.). Pistes didactiques et chemins d'historiens. Extes offerts à Henri Moniot. Paris: L'Harmattan, 2003. p. 241-263.

BRUNER, J. Acts of meaning. Cambridg, Mass.: Harvard University, 1990.

CALVANI, A. Il bambino, il tempo, la storia. Firenze: La Nuova Italia, 1988.

COOPER, H. Didáctica de la historia en la educación infantil y primaria. Madrid: Morata, 2002.

EVANS, R.W. A critical approach to tecahing United States history. In: Evans, R.W.; SAXE, D.W. (Org.). Handbook on teaching social issues. Washington, DC: National Council for the Social Studies (NCSS), 1996. p. 152-160.

FERRO, M. Visions de l'histoire et périodisation, une typologie. In: AA.VV. Périodes. La construction du temps historique. Actes du Ve Colloque d'histoire au present. Paris: Éditions de l'École des Hautes Études en Sciences Sociales et Histoire au présent, 1991. p. 99101 . 
FRAISSE, P. Psychologie du temps. 2. ed. cor. i aug. París: PUF, 1967. FRIEDMAN, W.J. (Ed.). The developmental psichology of time. New York: Academic Press, 1982.

GIRARDET, H. Problemas y perspectivas de investigación en didáctica de las ciencias sociales. La enseñanza-aprendizaje como coparticipación en los conocimientos. In: VVAA. La formación del profesorado y la didáctica de las ciencias sociales. Sevilla: Díada; AUPDCS, 1996. p. 135-149.

GIRARDET, H. Insegnare storia. Risorse e contesti per i primi apprendimenti. Firenze: La Nuova Italia, 2001.

HICKS, D.W. Lessons for the Future. The missing dimension in education. Oxford: Trafford, 2006.

HOBSBAWM, E. Sobre la historia. Barcelona: Crítica, 1998.

KOSELLECK, R. Futuro pasado. Para una semántica de los tiempos históricos. Barcelona: Paidós, 1993.

LAUTIER, N. Enseigner l'histoire au lycée. París: Colín, 1997.

MATOZZI, I. I bambini, il tempo, la storia: educazione temporale e curricolo di storia nella scuola elementare. In: C.I.D.I. di Firenze (a cura di). Tempo e spazio, dimensioni del sapere. Dalle ipotesi teoriche alle practiche didattiche. Milano: Mondadori, 1988. p. 65-81.

MATOZZI, I. Presentazione per il docente. La formazione del pensiero temporale negli adolescenti.. In Perillo, E. (a cura di). La storia. Istruzione per l'uso. Materiali per la formazione de competenze temporali degli studenti. Napoli: Tecnodid, 2002. p. 9-22.

MONTAGERO, J. Perspectives actualles sur la psychogenese du temps. L'Anné Psichologique, p. 433-460, 1984.

PAGÈS, J. Aproximación a un currículum sobre el tiempo histórico. In: Rodríguez FRUTOS, J. (Ed.). Enseñar historia. Nuevas propuestas. Barcelona: Laia; Cuadernos de Pedagogía, 1989. p. 107-138.

PAGÈS, J. El tiempo histórico: ¿Qué sabemos sobre su enseñanza y su aprendizaje? Análisis y valoración de los resultados de algunas 
investigaciones. In: AAVV. Aspectos didácticos de Ciencias Sociales, 13. Zaragoza: ICE; Universidad de Zaragoza, 1999. p. 241-278.

PAGÈS, J. Tiempos de cambios... ¿Cambios de tiempos?. Sugerencias para la enseñanza y el aprendizaje del tiempo histórico a inicios del siglo xxi. In: Ferraz, F. (Org.). Reflexões sobre espaço-tempo. Coleção Textos de Graduação, v. 3, Salvador: UCSAL; Quarteto editora, 2004. p. 35-53.

PAGÈS, J.; SANTISTEBAN, A. La enseñanza del tiempo histórico: una propuesta para superar viejos problemas. In: AAVV. Un currículum de Ciencias Sociales para el siglo XXI. Qué contenidos y para qué. Sevilla: Díada, 1999. p. 187-207.

PAGÈS, J.; SANTISTEBAN, A. Cambios y continuidades: aprender la temporalidad histórica. In: FonseCA, S.G. (Ed.). Ensino fundamental. Conteúdos, metodologias e práticas. Campinas: Alínea, 2009. p. 197-240.

PIAGET, J. El desarrollo de la noción de tiempo en el niño. México: Fondo de Cultura Económico, 1978.

RAMOS, R. (Comp.). Tiempo y sociedad. Madrid: CIS; Siglo XXI, 1992.

SANTISTEBAN, A. Aprender el tiempo histórico: deconstruir para reconstruir. Historiar, p. 141-150, 1999.

SANTISTEBAN, A. Temps al temps a l'escola. Perspectiva Escolar, p. 332: 9-15, 2009.

SANTISTEBAN, A.; PAGÈS, J. La enseñanza de la historia en la educación primaria. In: CASAS, M; TOMÀS, C. (Coord.). Educación primaria. Orientaciones y recursos. Barcelona: Wolters Kluwer Educación, 2006. p. 129-160.

SEGA, T. Lo specchio dotato di memoria: la fotografia. In: FALTERI, P.; Lazarin, G. Tempo. Memoria. Identita. Orientamenti per la formazione storica di base. Firenze: La Nuova Italia, 1986.

STEIN, N.L.; GLENN, C.G. Children's concept of time: the development of a story schema. In: Friedman, W.J. (Ed.). The developmental psichology of time. Nova York: Academic Press, 1982. p. 255-282. 
STOW, W.; HAYDN, T. Issues in the teaching of chronology. In: Arthur, J.; Phillips, R. (Ed.). Issues in history teaching. London: Routledge, 2000. p. 83-97.

THORNTON, S.J.; VUKELICH, R. Effects of children's understanding of time concepts on historical understanding. Theory and Research in Social Education, v. 16, n. 1, p. 69-82, 1988.

TUNÓN DE LARA, M. El movimiento obrero en la historia de España. Barcelona: Laia, 1985.

WHITAKER, P. Primary schools and the future. Celebration, challenges and choices. Buckingham, Ph: Open University Press, 1997. 